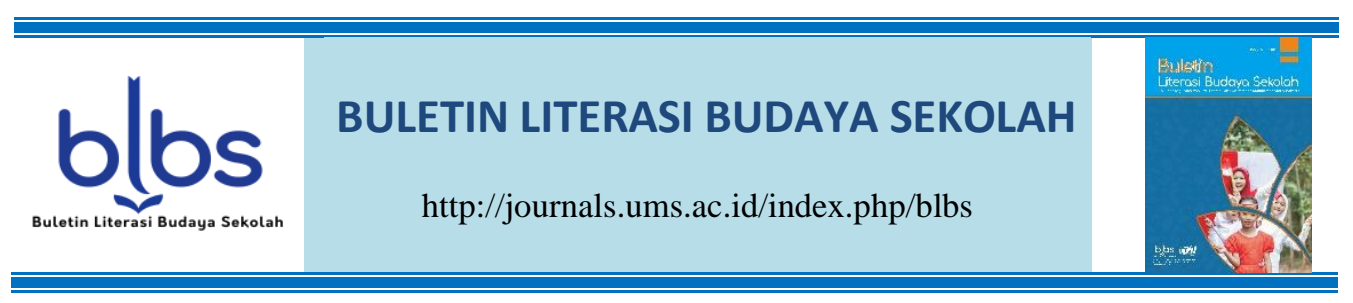

\title{
MENINGKATKAN KETERAMPILAN SISWA DALAM PEMBELAJARAN DATABASE, MAIL SERVER DI SEKOLAH SMKN 9 SURAKARTA
}

\author{
Luxman Aji Prakoso ${ }^{1}$, Abu Qosim Almisfalah ${ }^{2}$, \& Hendra Arief Kurniawan ${ }^{3}$ \\ $1,2,3$ Universitas Muhammadiyah Surakarta \\ Jalan A.Yani Tromol Pos 1, Surakarta, Indonesia \\ Email: ${ }^{1}$ Ajiprakos0831@gmail.com, ${ }^{2}$ Micfalah354@gmail.com, \\ 3ariefkurnia0430@gmail.com
}

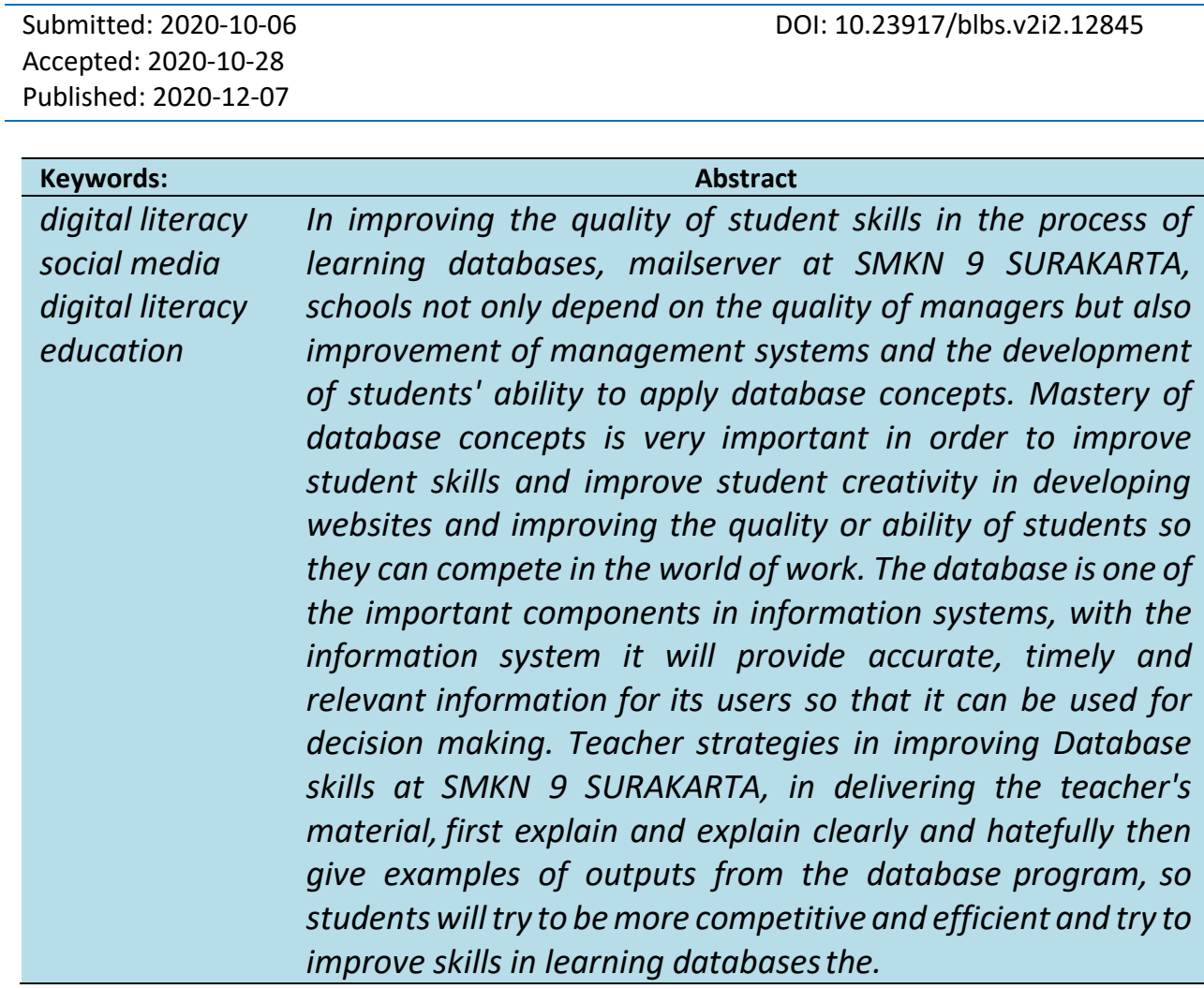

\section{PENDAHULUAN}

Menurut Edhy Sutanta (2014) Dalam bukunya yang berjudul Analisa Basis Data adalah sebagai berikut: "Basis data bisa dipahami sebagai suatu kumpulan data terhubung (interrelated data) yang disimpan dengan bersama-sama pada suatu media, tanpa mengatap satu dan yang lainnya atau tidak memerlukan suatu kerangkapan data (meskipun ada maka kerangkapan data itu harus seminimal mungkin dan terkontrol (controlled redundancy), data disimpan dengan cara tertentu sehingganya mudah untuk digunakan dan ditampilkan kembali, data bisa digunakan satu atau bahkan lebih program- program aplikasi secara optimal, 
data disimpan tanpa ketergantungan dengan program yang akan menggunakannya, data disimpan sedemikian rupa sehingga proses pengambilan, penambahan, dan modifikasi data dapat dilakukan dengan sangat mudah dan terkontrol."

Keterampilan adalah kemampuan lebih yang ada pada diri seseorang untuk menyelesaikan atau melakukan pekerjaan. Jika pekerjaan itu di dalam pembelajaran, maka pekerjaan itu berupa tugas-tugas dalam belajar (Ahmad, 2017:77). Salah satu upaya guru dalam meningkatkan keterampilan siswa yakni dengan membuat siswa aktif dalam kegiatan pembelajaran. Kegiatan pembelajaran didukung dengan metode, model dan strategi yang dirancang oleh guru agar kegiatan pembelajaran berpusat pada siswa (Rahmawati, Nugroho, \& Putra, 2014:41). Keterampilan menurut Qodratilah dalam Hidayat (2017:25) adalah kemahiran dan kecakapan untuk menyelesaikan tugas.

Kata pembelajaran sengaja dipakai sebagai padanan kata yang berasal dari bahasa Inggris Instruction. Kata Instruction mempunyai pengertian yang lebih luas daripada pengajaran. Jika kata pengajaran ada dalam konteks guru-murid di kelas (ruang) formal, pembelajaran atau Instruction mencakup pula kegiatan belajar mengajar yang tak dihadiri guru secara fisik. Oleh karena dalam Instruction yang ditekankan adalah proses belajar, maka usaha-usaha yang terencana dalam manipulasi sumber-sumber belajar agar terjadi proses belajar dalam diri siswa kita sebut pembelajaran. (Arief S. Sadirman dalam Asrori, 2013:165-166). Menurut Sudjana dalam Afandi, 2013:5) pembelajaran direncanakan dan dipersiapkan terlebih dahulu oleh guru dengan melibatkan siswa secara sistematik, ataukah suatu proses yang bersifat otomatis dari guru disebabkan telah menjadi pekerjaan rutin.

Pembelajaran pada hakikatnya adalah suatu proses, yaitu proses mengatur, mengorganisasi lingkungan yang ada di sekitar peserta didik sehingga dapat menumbuhkan dan mendorong peserta didik melakukan proses belajar. Pembelajaran juga dikatakan sebagai proses memberikan bimbingan atau bantuan kepada peserta didik dalam melakukan proses belajar. Proses pembelajaran ditandai dengan adanya interaksi edukatif yang terjadi, yaitu interaksi yang sadar akan tujuan (Pane \& Dasopang, 2017: 338).

Dalam era global saat ini sistem informasi merupakan bagian yang tak terpiasahkan dari suatu organisasi di mana sistem informasi menghasilkan hasil keluaran (output) dengan menggunakan masukan (input) dan berbagai proses yang diperlukan untuk memenuhi tujuan tertentu dalam suatu kegiatan manajemen. Database manajemen sistem merupakan perangkat lunak yang dapat digunakan untuk mendefinisikan, menciptakan, mengola, dan mengendalikan pengaksesan basis data. Tugas dari database manajemen sistem adalah menyediakan lingkungan yang nyaman dan efisien untuk penyimpanan dan pengambilan data dari basis data. Pengelolaan manajemen basis data membutuhkan suatu perangkat / tools untuk dapat mengelolanya, sehingga manajemen basis data dapat terus dikelola dan terus ditingkatkan kinerjanya. Dengan adanya sistem informasi maka suatu organisasi akan berusaha untuk lebih kompetitif dan efisien yang pada akhirnya menambah nilai untuk mendapatkan, mengubah dan mendistribusikan informasi dengan tujuan meningkatkan pengambilan keputusan, meningkatkan kirnerja organisasi dalam mencapai tujuan organsisasinya. Sebuah Sistem Informasi yang 
efektif menyediakan informasi yang akurat, tepat waktu dan relevan bagi penggunanya sehingga dapat digunakan untuk pengambilan keputusan.

Data adalah bahan baku informasi dan dikumpulkan dalam suatu basis-data (database) agar pengumpulan, penyimpanan, pemeliharaan, pengolahan, dan pengamanannya dapat dilaksanakan secara effektif dan effisien diperlukan manajemen data, sehingga suatu informasi tersebut dapat menjadi informasi yang tepat guna, tepat waktu, akurat dan relevan. Diskriptif singkat ini merupakan panduan bagi kami guna meningkatkan keahlian siswa dalam pembelajaran data base server local yang menggunakan software xampp. Meningkatkan kreativitas siswa dalam mengembangkan website. Sehingga tujuan pembelajaran dapat tercapai, dengan demikian kita dapat mengimplementasikannya di sekolah.

Database atau basisdata di dalam buku Simarmata \& Paryudi dalam Octafian (2011:150), sebagai berikut: a. Menurut Stephens dan Plew (2000), adalah mekanisme yang digunakan untuk menyimpan informasi atau data. b. Menurut silberschatz, dkk (2002) mendefenisikan basisdata sebagai kumpulan data berisi informasi yang sesuai untuk sebuah perusahaan. c. Menurut Ramakrishnan dan Gehrke (2003) menyatakan basisdata sebagai kumpulan data, umumnya mendeskripsikan aktivitas satu organisasi atau lebih yang berhubungan. $d$. Menurut McLeod, dkk (2001), adalah kumpulan seluruh sumber daya berbasis komputer milik organisasi.

Tujuan perancangan basisdata dalam Khotijah (2016:155) adalah : 1. untuk memenuhi informasi yang berisikan kebutuhan-kebutuhan user secara khusus dan aplikasi-aplikasinya 2. memudahkan pengertian struktur informasi 3. mendukung kebutuhan-kebutuhan pemrosesan dan beberapa obyek penampilan (response time, processing time, dan storage space).

Database merupakan aspek yang sangat penting dalam sistem informasi karena berfungsi sebagai gudang penyimpanan data yang akan diolah lebih lanjut. Database menjadi penting karena dapat mengorganisasi data, menghidari duplikasi data, menghindari hubungan antar data yang tidak jelas dan juga update yang rumit. Proses memasukkan dan mengambil data ke dan dari media penyimpanan data memerlukan perangkat lunak yang disebut dengan sistem manajemen database (database management system/DBMS) (Mulyodiputo, 2018:17).

Mail server (juga dikenal sebagai sebuah mail transfer agent atau MTA, mail router atau mailer Internet) adalah sebuah aplikasi yang akan menerima email masuk dari pengguna lokal (orang-orang dalam satu domain) dan jarak jauh pengirim dan meneruskan email keluar untuk pengiriman. Sebuah komputer yang didedikasikan untuk menjalankan aplikasi tersebut juga disebut sebagai mail server (Prakoso dkk, 2017:1873).

\section{METODE}

Penelitian yang digunakan penulis adalah penelitian kualitatif, penelitian yang bersifat deksriptif dan cenderung menggunakan analisis yang dapat menjelaskan fenomena dengan sedalam-dalamnya melalui pengumpulan data. Dalam penelitian ini, terdapat dua data observasi yang dihimpun berupa data primer dan data sekunder, data primer merupakan data observasi, dan wawancara dari narasumber, sedangkan data sekunder berupa data dokumentasi. Lokasi penelitian yang dilaksanakan di SMK Negeri 9 Surakarta, dimulai pada tanggal 28 Januari 2020 
sampai tanggal 10 Februari 2020. Kegiatan dalam penelitian ini dilakukan dalam bentuk observasi dengan tujuan untuk mengetahui seberapa besar antusiasme peserta didik SMK Negeri 9 Surakarta. Pengumpulan data yang digunakan dalam penelitian adalah observasi, dokumentasi, dan wawancara. Teknik observasi dilakukan selama 3 jam yang diamati pada mata pelajaran Multimedia. Observasi dilakukan untuk mengamati kegiatan pembelajaran mengenai suasana/kondisi kelas, waktu kegiatan pembelajaran, metode pembelajaran, dan interaksi antara guru dan peserta didik. Pengumpulan data selanjutnya menggunakan teknik dokumentasi, teknik dokumentasi digunakan untuk mendapatkan data yang berupa portofolio, arsip, rekaman, dan laporan siswa. Teknik dokumentasi dapat membantu dalam pengumpulan data penelitian, pelaksanaan pada pembelajaran di kelas. Pengambilan data selanjutnya, teknik wawancara. Wawancara dilakukan dengan member pertanyaan mengenai metode. Mahasiswa mengumpulkan informasi secara langsung dengan cara bertanya kepada guru atau siswa seperti kegiatan, peraturan, waktu dan data-data sekolahan.

\section{HASIL DAN PEMBAHASAN}

Pada observasi yang kami lakukan di SMKN 9 SURAKARTA, kami meneliti beberapa siswa jurusan multimedia, khususnya pada pembelajaran database,mail server, dapat diperoleh data bahwa siswa dapat mengembangkan berbagai hal tentang pembelajaran database dan website. Dalam proses pembelajaran tersebut siswa diajarkan tentang penggunaan software Xampp, Xampp sendiri ialah aplikasi server local yang biasanya di pakai untuk menghubungkan website ke database. Kami melihat bagaimana seorang guru tersebut menerangkan atau menjelaskan isi materi yang diberikan kepada siswa sangat jelas dan terperinci, tentunya itu secara tidak langsung sebagian dari upaya untuk meningkatkan kemampuan siswa atau menambah keterampilan siswa dalam mempelajari materi database tersebut.

Dalam upaya meningkatkan keterampilan atau menambah kemampuan siswa dalam mempelajari database tidak cukup hanya mempunyai guru yang ahli atau guru yang menguasai materi database, tentunya sekolah juga harus mempunyai alat atau perlengkapan yang lengkap sebagai sarana belajar siswa dalam menambah keterampilan dalam mempelajari database. Yang kami lihat di sekolah SMKN 9 SURAKARTA, sekolah tersebut sudah mempunyai guru yang menurut kami sudah ahli dan mampu menjelaskan materi yang di berikan dengan sangat jelas dan perlengkapan praktik yang dimiliki sekolah SMKN 9 SURAKARTA juga sudah lengkap dan memadai, sehingga siswa yang menerapkan materi tersebut tidak kesulitan dan mudah di mengerti.

Siswa yang sudah berhasil akan mengembangkan website yang sudah dibuat dan dihubungkan ke database dengan menambahkan beberapa tampilan yang ada di website agar lebih menarik. Nilai itulah yang di ambil untuk nilai plus atau apresiasi yang diberikan kepada siswa tersebut. Kami meneliti beberapa siswa yang berhasil menerapkan materi yang diberikan oleh guru dan setelah selesai sebagian siswa mengembangkan website yang dibuat dengan berbagai macam, seperti menambahkan background, backsound, link, dan mengedit tampilan website agar lebih menarik sehingga ada nilai khusus yang diambil untuk ketrampilan tersebut serta menjadikan contoh bagi siswa yang lainya. 


\section{SIMPULAN}

Berdasarkan Observasi yang kami lakukan dapat ditarik kesimpulan materi pembelajaran data base pada siswa sangat penting dan berguna karena mempunyai prospek kerja yang luas. Dengan adanya strategi atau metode pembelajaran yang baru di era digital saat ini, tentunya akan menambah semangat belajar siswa, serta akan menambah keterampilan di bidang pemrograman web atau web server yang di mana ketrampilan tersebut akan diseleksi untuk maju di event pemrograman web atau lomba pemrograman web server. Dalam menambah keterampilan atau kemampuan siswa tidak cukup hanya mengandalkan guru yang ahli atau menguasai materi tersebut tetapi harus diimbangi dengan perlengkapan atau sarana yang lengkap untuk malakukan proses pembelajaran supaya siswa lebih terampil dan mudah menguasai materi database tersebut.

\section{DAFTAR PUSTAKA}

Rahmawati, D., Nugroho, S.E., \& Putra N.M.D. (2014). Penerapan Model Pembelajaran Kooperatif Tipe Numbered Head Together Berbasis Eksperimen untuk Meningkatkan Keterampilan Proses Sains Siswa SMP. Unnes Physics Education Journal, 3(1), 41-45.

Asrori, Mohammad. (2013). Pengertian, Tujuan dan Ruang Lingkup Strategi Pembelajaran. Madrasah, 5(2), 163-188.

Afandi, Muhamad., Chamalah, Evi., \& Wardani, Oktarina Puspita. (2013). Model dan Metode Pembelajaran di Sekolah. Semarang: Sultan Agung Press.

Pane, Aprida., \& Dasopang, Muhammad Darwis. (2017). Belajar dan Pembelajaran. Fitrah, 3(2), 333-352.

Ahmad, Arifin. (2017). Penerapan Permainan Bahasa (Katarsis) untuk Meningkatkan Keterampilan Membaca Siswa Kelas Iv A Sd Negeri 01 Metro Pusat. Edu Humaniora, 9(2), 75-83.

Hidayat, M.Arif., Anwar, Eli., dan Hidayah, Noer. (2017). Pendidikan Non Formal dalam Meningkatkan Keterampilan Anak Jalanan. Dudeena, 1(1), 31-42.

Octafian, D.Tri. (2011). Desain Database Sistem Informasi Penjualan Barang (Studi Kasus : Minimarket "Grace" Palembang). JURNAL TEKNOLOGI DAN INFORMATIKA (TEKNOMATIKA), 1(2), 148-157.

Khotijah, Siti. (2016). Desain Database Sistem Informasi Akademik pada Lembaga Pendidikan Tinggi. Faktor Exacta, 9(2), 154-165.

Mulyodiputro, M.Dermawan. (2018). Perancangan Database Sistem Informasi Apotik Menggunakan MySQL pada Apotik Cemara The Pharmacy Information System Database Design Using MySQL in the Pharmacy Cemara Farma. SIJ, 1(1), 16-19.

Prakoso, Galih Dwiyan., Periyadi., \& Andrian, Henry Rossi. Implementasi Keamanan Mail Server Zimbra Menggunakan Spamassassin dan Whitelist Pada Linux Centos 7 Implementation Of Zimbra Mail Server Security Using Spamassassin And Whitelist On Centos 7. e-Proceeding of Applied Science, 3(3), 1872-1882. 